\title{
In-field assessment of batteries and PV modules in a large photovoltaic rural electrification programme
}

\author{
L.M. Carrasco , L. Narvarte, F. Martínez-Moreno, R. Moretón
}

\begin{abstract}
A B S T R A C T
Assuring the sustainability of quality in photovoltaic rural electrification programmes involves enhancing the reliability of the components of solar home systems as well as the characterization of the overall programme cost structure. Batteries and photovoltaic modules have a great impact on both the reliability and the cost assessment, the battery being the weakest component of the solar home system and consequently the most expensive element of the programme. The photovoltaic module, despite being the most reliable component, has a significant impact cost-wise on the initial investment, even at current market prices. This paper focuses on the in-field testing of both batteries and photovoltaic modules working under real operating conditions within a sample of 41 solar home systems belonging to a large photovoltaic rural electrification programme with more than 13,000 installed photovoltaic systems. Different reliability parameters such as lifetime have been evaluated, taking into account different factors, for example energy consumption rates, or the manufacturing quality of batteries. A degradation model has been proposed relating both loss of capacity and time of operation. The user - solar home system binomial is also analysed in order to understand the meaning of battery lifetime in rural electrification.
\end{abstract}

\section{Introduction}

Big programmes installing thousands of SHS (solar home systems) are a hope for millions of people without access to electricity. However, many experiences [1-11] have had problems because real O\&M (operation and maintenance) cost are much larger than expected. This is rooted on the decentralized character of this application, which strongly amplifies the economic impact of any technical problem (travelling for substituting a damaged element can cost tens of times the cost of the element itself). Hence, knowledge of SHS components becomes essential when designing sustainable SHS programmes.

The Instituto de Energía Solar - Universidad Politécnica de Madrid (IES-UPM) is carrying out the assessment of the SHS reliability and O\&M costs of the PVRE (photovoltaic rural electrification) programme of Morocco, the so-called PERG - Programme d'Electrification Rurale Global. This programme is relevant because of its size (more than 13,000 SHSs, up to a total of $1.08 \mathrm{MW}$, were installed between 2005 and 2008), and because a complete maintenance database, with more than 80,000 maintenance inputs recorded over a period of 5 years including the operating costs, has been made available. The study aims to identify the key points involved in the sustainability of quality in big PVRE programmes with long maintenance periods.

The tender, launched in 2004, required a standardized SHS made up of a PV module of at least $75 \mathrm{~W}$, a lead acid battery of $150 \mathrm{Ah} \mathrm{C}_{20}$, a charge controller of $15 \mathrm{~A}$ and four lamps of 7 and $11 \mathrm{~W}$ (see Fig. 1).

A previous paper [12] showing the PERG programme cost assessment concluded that the overall programme cost, including installation, management and ten years of O\&M, reached 1575 $€ / S H S$, of which, battery represents the most expensive part of the programme: $18.5 \%$ of the overall cost and $25 \%$ of the O\&M cost. Moreover, the elevated 10 -year $0 \& M$ cost $(760 € / S H S)$ indicates that there is an economical imbalance in the development of this activity, in which the fees that SHS's users pay for the maintenance service is just $591 € /$ SHS.

Additionally, a reliability study based on actual SHSs failures [13] has shown that lamps and charge controllers have a constant yearly failure rate of $6.0 \%$ and $3.7 \%$ respectively. Corresponding MTTF 
$75 \mathrm{~W}_{\mathrm{p}} \mathrm{PV}$ module

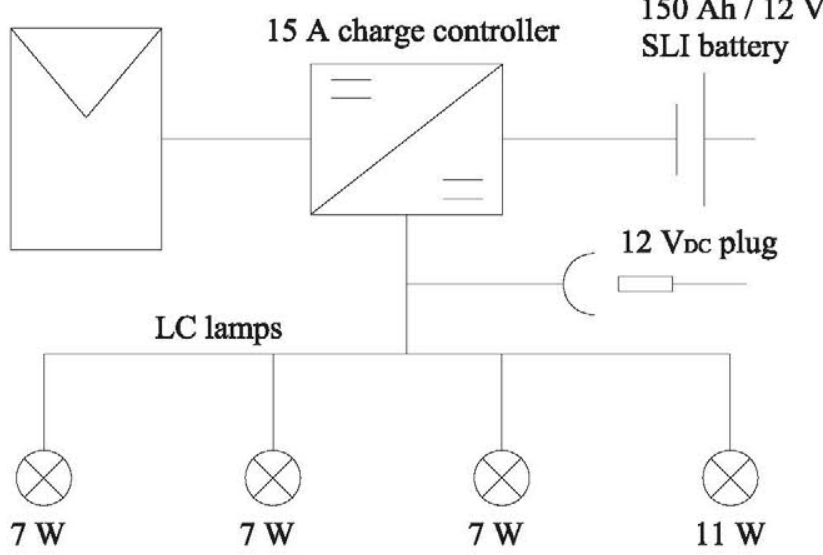

Fig. 1. PERG SHS single line diagram. It is made up of a $75 \mathrm{~W}_{\mathrm{p}}$ PV module, a $15 \mathrm{~A}$ charge controller, a $150 \mathrm{Ah} \mathrm{C}_{20}$ battery, four compact fluorescent lamps and a $12 \mathrm{~V}_{\mathrm{DC}}$ plug.

(mean time to failure) values are 27 and 17 years. However, the battery, affected by ageing factors, presented a variable failure rate and its MTTF was 5.5 years.

A further analysis of the failure database showed that it just included the completely dead batteries that required replacement by new ones. International technical standards consider that leadacid batteries are dead when the remaining capacity drops below $80 \%$ of their initial capacity. Nevertheless, in PVRE, batteries operate even when the remaining capacity is much lower than $80 \%$, namely until the user perceives that the battery must be replaced. Consequently, further studies to analyse the capacity degradation of the batteries and to establish their real lifetime and reliability are required.

On the other hand, PV modules were not analysed in the previous reliability study because of the very low failure data found in the database: just 20 failures over more than 13,000 installed PV modules. This low failure rate did not allow a proper reliability study to be carried out, but it indicated that PV modules have a very high reliability as regards the other components.

This paper describes two in-field assessments carried out in the Moroccan PERG programme to determine both, the capacity deterioration of the batteries and the quality status of the PV modules when operating under real conditions in a sample of 41 SHSs from 6 provinces (Fig. 2). In 32 of these dwellings a datalogger has been installed to record the battery's operating parameters.
Table 1

Battery data sheet [14].

\begin{tabular}{ll}
\hline Storage capacity & $150 \mathrm{Ah} \mathrm{C}_{20}$, at $20^{\circ} \mathrm{C}$ and $10.8 \mathrm{~V}(1.8 \mathrm{~V}$ per cell $)$ \\
& as final discharging voltage \\
Autonomy & 5 days $\left(\mathrm{DOD}=40 \%\right.$ and daily load $\left.L_{\mathrm{d}}=12 \mathrm{Ah}\right)$ \\
Electrolyte density & $1.26 \mathrm{~g} / \mathrm{cm}^{3}$ at $20^{\circ} \mathrm{C}$ \\
\hline
\end{tabular}

The PERG region is located, partly, in a mountainous area ( $50 \%$ of the region is covered by 3 mountain ranges: the Medium Atlas, the Grand Atlas and the Anti-atlas), and partly by wide desert areas. Climate varies between the different areas, but it predominates the continental climate with very hot summers and cold winters (it becomes very dry and extremely warm during the long summer, especially on the southern lowlands). In the mountainous regions rainfall can reach up to $350 \mathrm{~mm}$ per year and snow also fall in winter. Precipitation in the south can reach $100 \mathrm{~mm}$ per year Horizontal solar irradiation varies between 4.7 and more than $5.5 \mathrm{kWh} / \mathrm{m}^{2} /$ day as yearly average.

\section{Battery testing}

The standardized SHS model installed in the PERG programme has been described in Fig. 1.

The installed battery is a flat plate, lead-acid, SLI (startinglighting-ignition) technology produced in Morocco (data sheet in Table 1). Note that this is the lowest cost battery technology used in PV stand-alone applications, and in this case, it reached a cost of $100 € /$ SHS $(0.06 € / \mathrm{Wh})$. On the other hand, the SHS's battery was sized for an autonomy of 5 days (tender condition), which means that considering $150 \mathrm{Ah}$ as nominal capacity $\left(\mathrm{C}_{\text {nom }}\right)$, and a designed DOD (depth of discharge) $=40 \%$, it can be deduced that the design load was $L_{\mathrm{d}}=12 \mathrm{Ah} /$ day.

The CC (charge controller) is a PHOCOS CML-15 model, which has a PWM (pulse width modulation) control including a temperature compensation algorithm. It protects the battery against deep discharge cutting the load consumption when the battery reaches $11.4 \mathrm{~V}$ (at $25^{\circ} \mathrm{C}$ ), as required by the PERG technical specifications imposed by the programme promoter (the Moroccan National Electric Utility: ONE - Office National d'Electricité). Other features can be found in the manufacturer datasheet [15].

In order to analyse battery ageing rates, we have substituted existing batteries with new ones at 40 SHS already in operation since more than 5 years. In this way, energy consumption habits

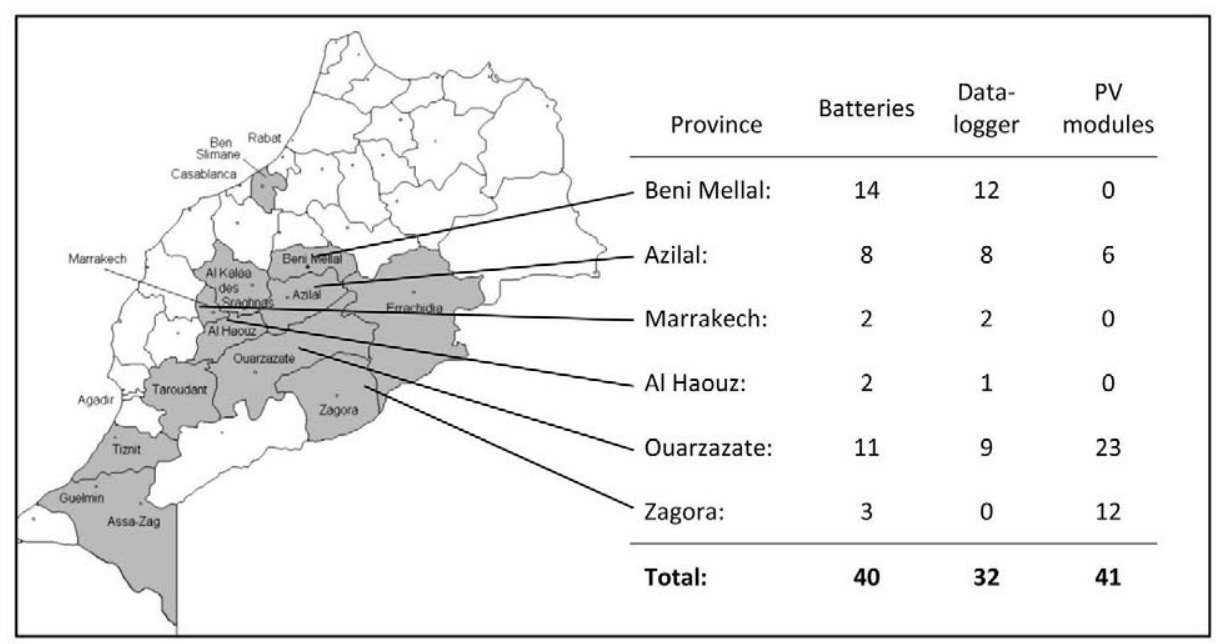

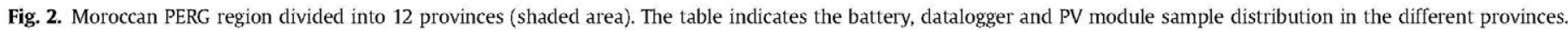


Table 2

Different battery capacity tests achieved during their operation under real conditions.

\begin{tabular}{llllll}
\hline Test & 1.1 & 1.2 & 2 & 3 & 4 \\
\hline Month & 0 & 0 & 6 & 12 & 18 \\
& (as delivered by the manufacturer) & (after initial full charge) & & \\
\hline
\end{tabular}

must be stabilized. 32 of these SHSs have also been equipped with the PHOCOS CX20 model charge controllers [15], capable of recording past daily energy consumption values.

Several capacity tests have been performed in these new batteries throughout their operating life as detailed in Table 2.

Tests 2, 3 and 4 have been carried out by temporally collecting the batteries from the households and putting them together on a testing stand (Fig. 3) for around one week, during which the SHS keeps working through a spare battery. Initial full charging was accomplished by means of largely available domestic battery chargers, leaving the batteries at least for $12 \mathrm{~h}$ in flotation after the end of the charge. Then, each battery was discharged through two $50 \mathrm{~W}$ halogen lamps. This way, the discharging current, $I_{\mathrm{D}}$, was close to $C_{20}\left(I_{\mathrm{D}} \approx 2 \times 50 \mathrm{~W} / 12 \mathrm{~V}=8.3 \mathrm{~A}\right)$. Discharging was maintained until the battery voltage $V_{\mathrm{B}}$ reached $10.8 \mathrm{~V}, I_{\mathrm{D}}, V_{\mathrm{B}}$, and ambient temperature was manually recorded every $30 \mathrm{~min}$. So, the accuracy of the measurement is about $\pm 4 \mathrm{Ah}$. As the temperature affects the results, they have been corrected $0.5 \% /{ }^{\circ} \mathrm{C}$. So, we estimate an accuracy of the result of about $6 \%$. The measurements of the electrolyte density were also taken both before and after performing the tests for each battery.

Finally, one of the most degraded batteries was opened up, after Test 4 , and the plates extracted for direct visual inspection.

Fig. 4 shows the voltage evolution of one of the batteries in Test 1.2. Note that the voltage drops slowly during the discharging process but it falls quickly when voltage is close to $11.4 \mathrm{~V}$, which means that the DOD when the batteries reach the CC low voltage disconnection is practically $100 \%$. This reveals that the protection threshold was incorrect and it was not protecting the batteries, although, as will see below, this does not seem very relevant, since excessive discharging rates are not common.

\subsection{Capacity results}

Fig. 5 shows the battery capacity histograms as delivered (Test 1.1) and after the initial charge (Test 1.2). Fig. 6 describes the time evolution of the capacity once the batteries are in operation (Test 1.2, 2, 3 and 4). Table 3 summarizes the corresponding mean and standard deviation values.

The following comments apply.

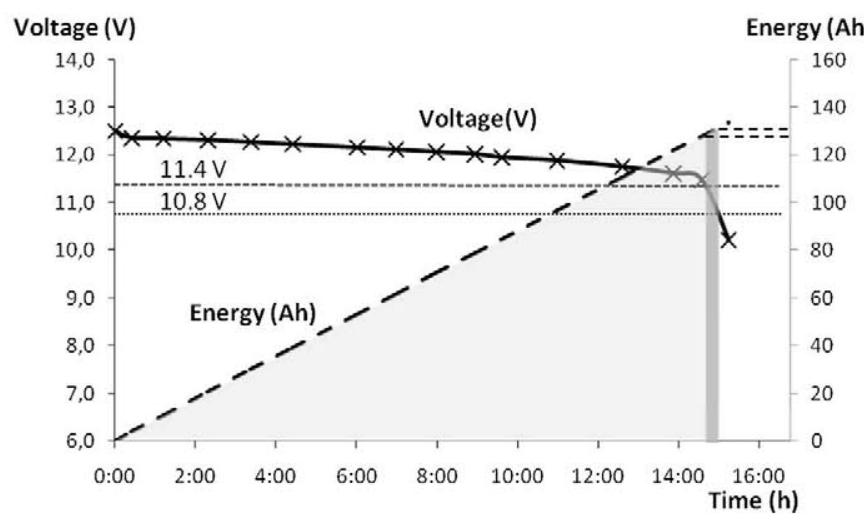

Fig. 4. Voltage and energy curves of one of the battery discharging tests. The crosses over the voltage line represent the different readings taken during the test. The dashed line over the light grey area represents the capacity extracted from the battery when the charge controller disconnects the battery at $11.4 \mathrm{~V}$. The dashed line over the thin and darker area shows the remaining capacity of the battery between 11.4 and $10.8 \mathrm{~V}$.

- Low mean and large spread capacity values of delivered batteries suggest, respectively, insufficient 'formation' of the plates and poor manufacturing quality. It is worth remembering that incompletely formed plates contain not only proper active materials (lead dioxide on the positive electrodes and sponge lead on the negative electrodes) but also remnants of other materials $\left(\mathrm{PbO}, \mathrm{PbSO}_{4}\right.$ ) which lead to initial capacities that are below the nominal values. Moreover, these remnants induce anomalous crystallization around them. Thus, this initial poor quality acts as a seed for accelerated degradation. This quality problem is also

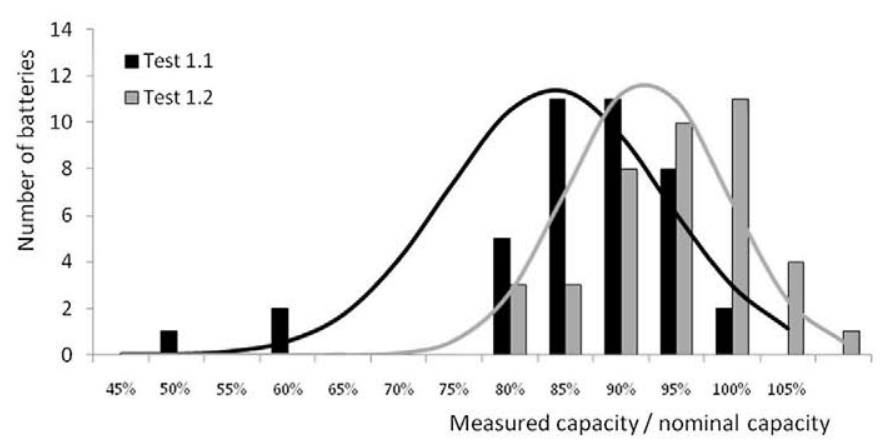

Fig. 5. Capacity distribution of batteries from tests 1.1 (after delivery by the manufacturer) and 1.2 (after initial full charge). Note that characteristic capacity distribution of test 1.1 is broader than the one of test 1.2 and its mean value is shifted to the left.

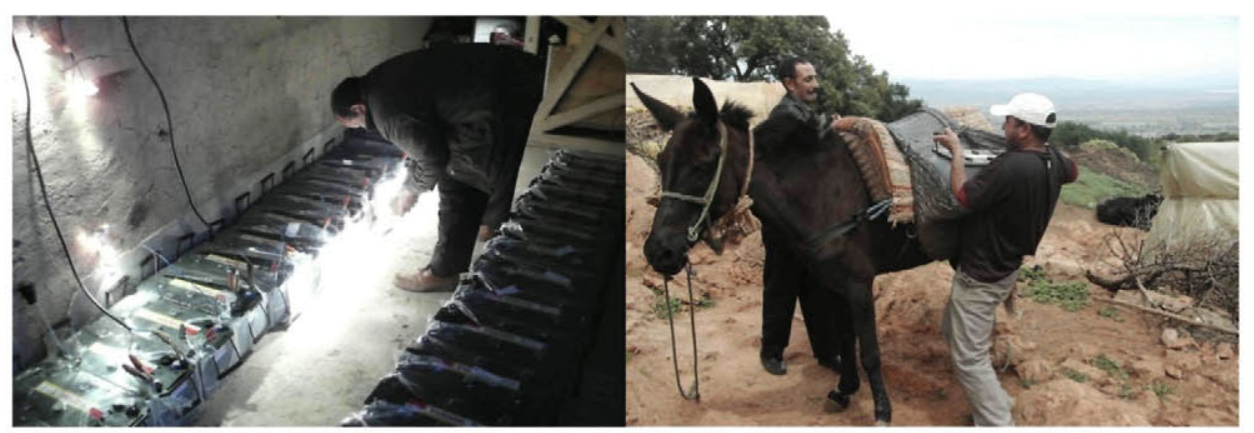

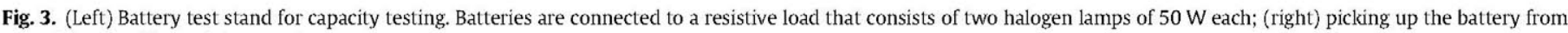
one of the dwellings of the sample. 


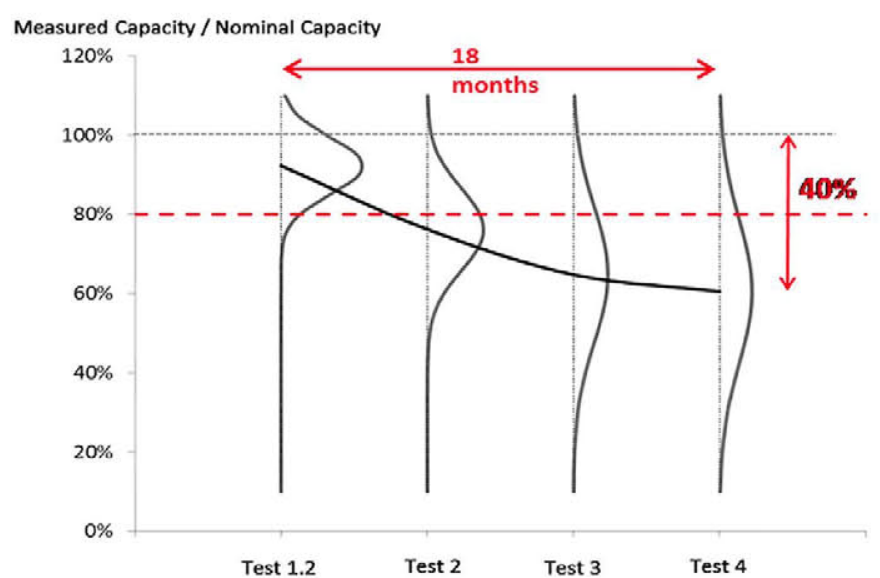

Fig. 6. Capacity representation of the entire battery sample on the Tests number 1.2, 2, 3 and 4 . Note that from Test 2, the average capacity is situated below $80 \%$ as regards the nominal capacity.

seen at the broad dispersion of the measured electrolyte density for the total battery set (see Fig. 7).

- The initial charge further helps the formation of the plates, leading to an increase in battery capacity. However, half the specimen shows still capacities below $95 \%$ of the nominal value, which is the recommended threshold for SHS battery acceptance (see the Universal Technical Standard for Solar Home Systems [16]). Large capacity spread still persists.

- Not surprisingly, subsequent observed degradation rates, with the batteries already in operation, are very high. An experimental model of capacity degradation has been derived simply by calculating the time that each battery is in use to reach the states corresponding to $80 \%, 70 \%, 60 \%$, and $50 \%$ of its nominal capacity. For each capacity state, there are some batteries that have reached that state (it could be defined as "failures") and others that do not reach that state ("survivors") [17]. For instance, there are 21 batteries that reached the degradation of $70 \%$ of the nominal capacity $\left(0.7 \mathrm{C}_{\text {nom }}\right)$ at some point during the 18 months of the testing period ("failures"), and 15 batteries that never reached this degradation ("survivors"). Fig. 8 shows that the unreliability function $\mathrm{F}(\mathrm{t})$ of the batteries that got $70 \%$ of their initial capacity fits a normal distribution. Furthermore, the mean value (or mean time to failure - MTTF) of each one of the normal fit distributions at different capacities have been calculated $\left(\mathrm{MTTF}_{80 \%}, \mathrm{MTTF}_{70 \%}, \mathrm{MTTF}_{60 \%}\right.$ and $\mathrm{MTTF}_{50 \%}$ ). Based on these averages, an experimental degradation function has been extracted relating the MTTF and the capacity degradation (Fig. 9).

The question of battery lifetime deserves further comment. Worldwide accepted standards $[18,19]$ indicate that batteries reach the end of their lifetime when the remaining capacity is below $80 \%$ of their initial capacity. In the case of adhering to this figure, the

Table 3

Corresponding capacity $\left(C_{20}\right)$ mean $(\mu)$ and standard deviation $(\sigma)$ for the different tests.

\begin{tabular}{llll}
\hline Test & $\mu \mathrm{C}_{20 \text { test }} / \mathrm{C}_{2 \text { 20nominal }}(\%)$ & $\mu \mathrm{C}_{20}(\mathrm{Ah})$ & $\sigma \mathrm{C}_{20}(\mathrm{Ah})$ \\
\hline 1.1 & 84 & 126 & 15 \\
1.2 & 92 & 138 & 11 \\
2 & 76 & 114 & 16 \\
3 & 65 & 97 & 25 \\
4 & 62 & 94 & 25 \\
\hline
\end{tabular}

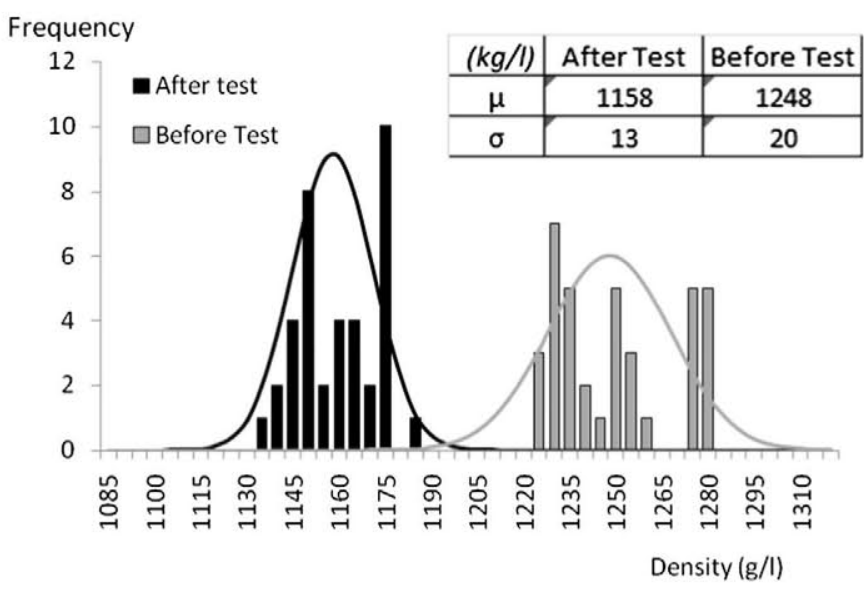

Fig. 7. Average density distribution from the six cells of each battery in Test 1.2 . Measurements were carried out before (grey colour) and after (black) the capacity tests. The high dispersion could be the result of poor manufacturing quality.

degradation function derived here implies that the SHS batteries concerned would have to be replaced before 1 year of operation. However, in reality batteries survive until the user complains about frequent blackouts. The PERG experience [13] shows that, in average, this happens after 5.5 years of operation. According to the previously derived degradation model, the remaining capacity of the battery at the end of this 'use-time' must be around $18 \%$ of the nominal value. That is, international battery standards and SHS user behaviour differ by factors between 4 and 6 , when the remaining capacity of the battery and lifetime are considered respectively. We think the explanation of this rather astonishing result relies on the fact that real energy consumptions are well below the standard values of design. Thus, most users are happy with its SHS even if it performs substantially below specifications.

At this point, it is important to clarify that the capacity that remains in the battery when it has $0.18^{*} C_{\text {ini }}$ does not necessarily match with the available capacity when the battery operates within the SHS, as evidenced below. Batteries at high capacity degradation levels have unexpected behaviours due to the elevated internal resistance when current is flowing in the charge and discharge states, and then, the charge controller's algorithms are

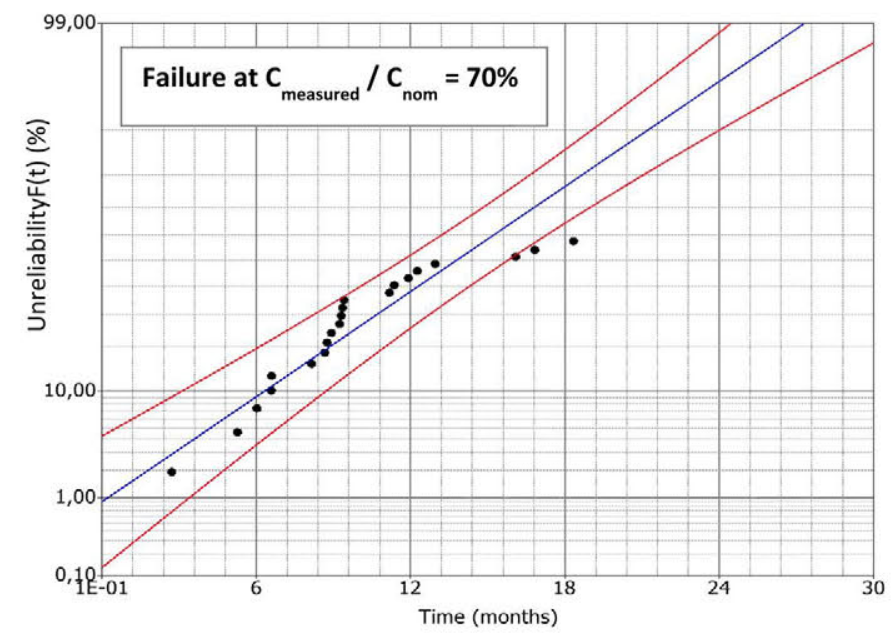

Fig. 8. Normal fit of the battery's unreliability $F(t)$, that is to say, the distribution of batteries that reach to $70 \%$ of their initial capacity as observed in the in-the-field battery testing. The two contour lines indicate the $95 \%$ confidence bounds of the fit distribution. 


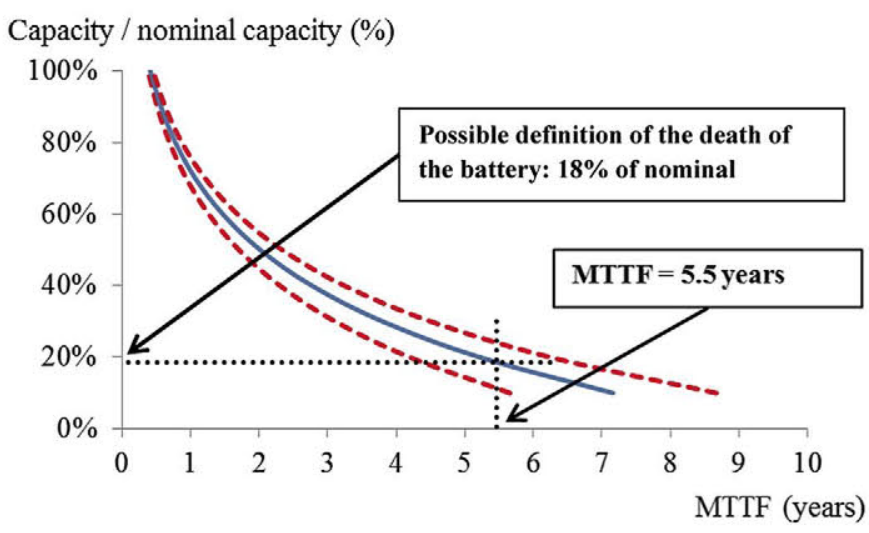

Fig. 9. Capacity tendency degradation of batteries extracted from the different capacity tests. When operation time reaches the MTTF $=5.5$ years, the remaining capacity of the battery is just $18 \%$. The two contour lines indicate the $95 \%$ confidence bounds of the degradation function.

malfunctioning. That is the case when PV module charges a degraded battery: the voltage in the terminals rises quickly because of a substantial increase in the internal resistance, and it is interpreted by the charge controller as final charge voltage, and it starts the floating charge mode even if the battery is not fully charged. Thus, the charge of the battery by the ensemble PV module - CC does not reach the full charge and then, the available capacity for the user is even lower than this $18 \%$ of $C_{\text {ini. }}$.

Finally, one of the most degraded batteries of the sample (it reached a capacity of less than $0.3 C_{\text {nom }}$ ) was inspected in the laboratory in order to check the actual state of the plates after carrying out the Test 4 . The electrolyte of the battery was completely removed and then the container was opened and the positive and negative plates of the cells extracted.

The inspection showed that most of the positive active mass was lost (shedding effect) and it was deposited at the bottom of the cells (see Fig. 10). The low physical resistance of the plates to the mechanical loads occurred during the cycling operation can be the cause of the loss of active mass, and thus, it produces the dramatic decrease in battery capacity and its early death.

\subsection{Observations on energy consumption}

After the analysis of the recorded data from the dataloggers it can be seen that:

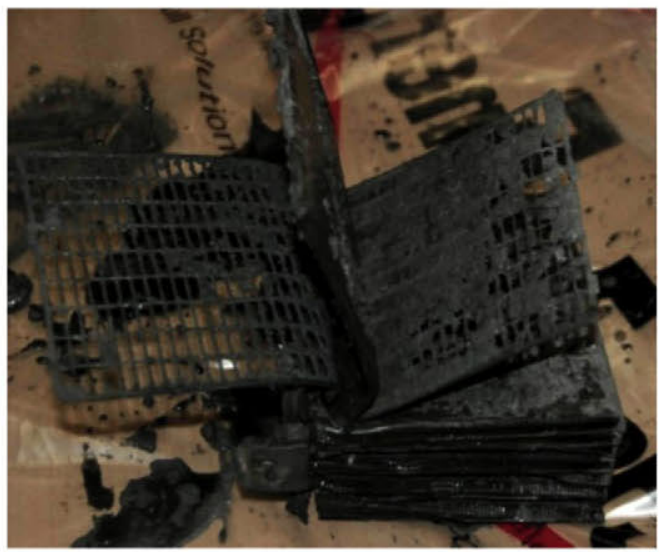

Fig. 10. Loss of active mass in the positive plates in one of the cells of the battery.
Table 4

Statistical results of the SOC in the morning and in the afternoon and days in which batteries are fully charged.

\begin{tabular}{llll}
\hline & $\begin{array}{l}\text { SOC } \\
\text { morning }(\%)\end{array}$ & $\begin{array}{l}\text { SOC } \\
\text { afternoon }(\%)\end{array}$ & $\begin{array}{l}\text { Battery full } \\
\text { charged days }(\%)\end{array}$ \\
\hline Mean $(\mu)$ & 66 & 70 & 74 \\
Median & 67 & 71 & 83 \\
Standard deviation $(\sigma)$ & 11 & 9 & 25 \\
Mode & 61 & 71 & 99 \\
\hline
\end{tabular}

- Mean daily energy consumption is $\mu_{\text {load }}=5.2 \mathrm{Ah} /$ day, and the standard deviation $\sigma_{\text {load }}=4.18 \mathrm{Ah} /$ day, which indicates that there is no standard load profile, but anyway, the real loads are on average lower than the load of design ( $12 \mathrm{Ah} /$ day).

- Despite that, some users are affected by blackouts, associated with the low voltage protection. This must happen on days in which energy consumption is exceptionally large. In fact, disconnections at the most affected houses are probably related with consumption surges during the week-end $(1 / 7=14 \%)$.

- Dataloggers indicate that the average battery's DOD (depth of discharge) ranges from between $30 \%$ and $50 \%$.

- The SOC (state of charge) recorded by the dataloggers after sunset is, in average, $70 \%$, while the percentage of days in which the dataloggers indicate full charge is $74 \%$. The results shown in Table 4 and the histogram in Fig. 11 indicate that even if most batteries reach full charge every day, the mean SOC after sunset is not $100 \%$. Assuming that in general the loads start from the afternoon onwards, it could be deduced that the algorithms that charge controllers use to calculate the SOC and the full charge state of the batteries are distorted by the battery degradation and do not work properly.

Given that the charge cycles of the batteries are characterized by low DOD (normal operation), with sporadic high DOD and load disconnections (exceptional operation), it can be established that the capacity degradation is related to both the capacity throughput [20], that is, the quantity of energy that passes through the battery, and with the number of disconnections due to low battery voltage that, according to the previous analysis, is not frequent but can dramatically affect the health of the battery.

In principle, with other circumstances being equal (solar radiation, ambient temperature, charge controller algorithms, etc.) the higher the energy consumption, the larger the battery degradation. In fact, this can be observed in reality, despite the anomalous behaviour of the high degraded batteries analysed here. Fig. 12

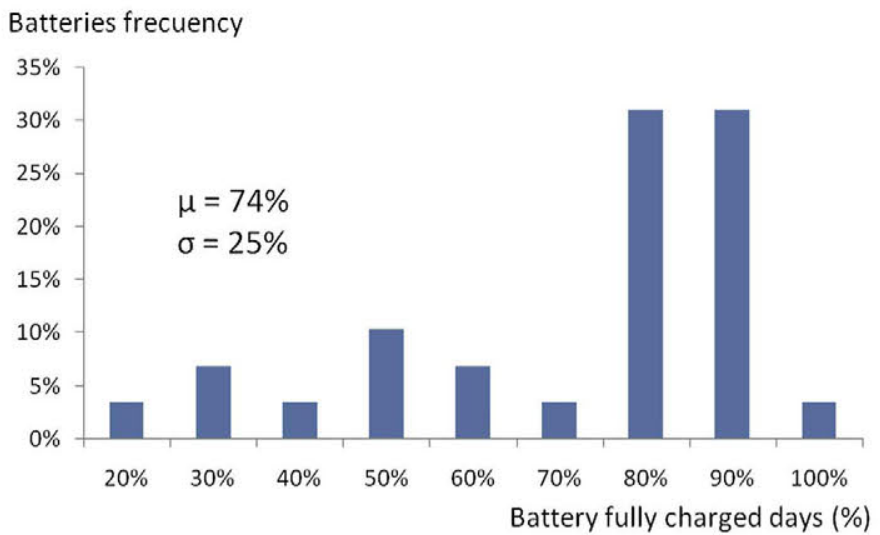

Fig. 11. Distribution of days in which the batteries reach the full charge as a percentage. 
shows a) the remaining capacity of the batteries after 18 months of operation ranked from least to most; b) the percentage of days with at least one disconnection of the load due to low battery voltage; and $\mathrm{c}$ ) the average daily load ( $\mathrm{Ah}$ ) of each battery during the 18 months of operation. The eight batteries in dark are those whose remaining capacity are equal to or lower than $50 \%$ of the $C_{\text {nom }}$.

The data represented in Fig. 12 (a) and (b), can be merged in a mathematical linear combination such as $z=A x+B y$, where $x$ represents the percentage of days of low battery disconnections, $y$ the average daily load (in percentage as well) and $z$ the capacity degradation. $A$ and $B$ are two parameters calculated for the best linear regression $(A=0.42 ; B=0.58$ ) (see Fig. 13).

These results suggest that battery's degradation is affected by the combination of both the normal and the exceptional operation roughly in the same proportion according to figures $A$ and $B$. The dispersion of the points is representative if social behaviours are involved, as is the case in SHS where the users are not only consumers, but also managers of the systems.

\section{In-the-field pv-module testing}

The PERG PV module model installed is an ISOFOTON IS-80S, consisting of 36 monocrystalline silicon cells and, at the moment of the testing, they had been working for a mean period of 6.15 years.

The testing method consisted of in-the-field measuring the I-V curve of the PV modules by means of a capacitive load [21]. This I-V curve has been extrapolated to STC (standard test conditions) to extract the peak power of the PV modules. Then, this actual peak power has been compared with the power of the flash report provided by the manufacturer as a part of the quality control carried out at the end of the manufacturing process.

During the test, the on-plane effective irradiance, $\mathrm{G}_{\text {eff, }}$ and cell temperature, $T_{\mathrm{C}}[22]$, have been measured from a coplanar

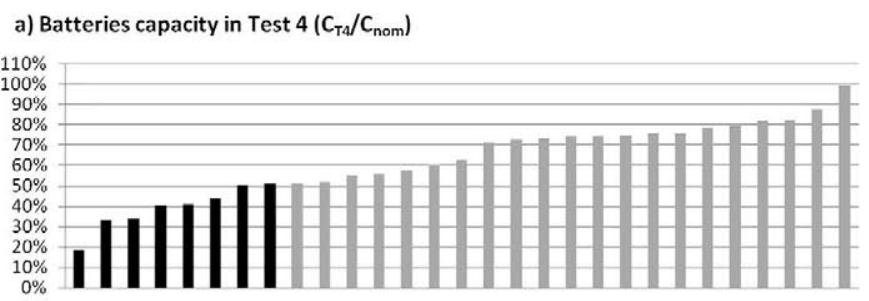

b) Days of low battery disconnections (\%)

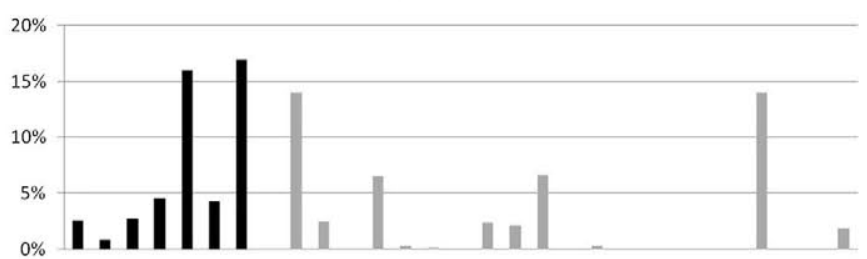

c) Average daily energy load (Ah)

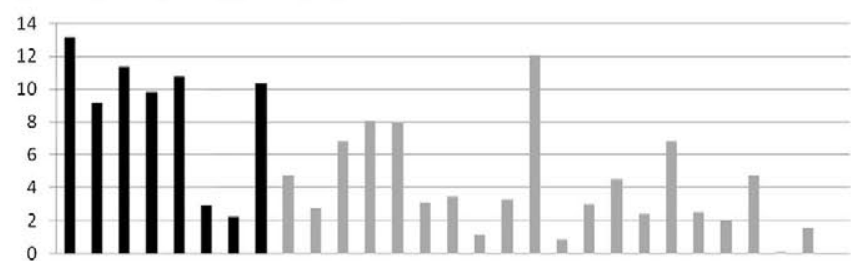

Fig. 12. Bars in the same position correspond to the same battery. (a) Remaining capacity of batteries after 18 months of operation measured in Test 4 . In dark, the 8 most degraded batteries (less than $50 \%$ capacity); (b) percentage of days with low voltage disconnections; (c) average daily load (Ah).

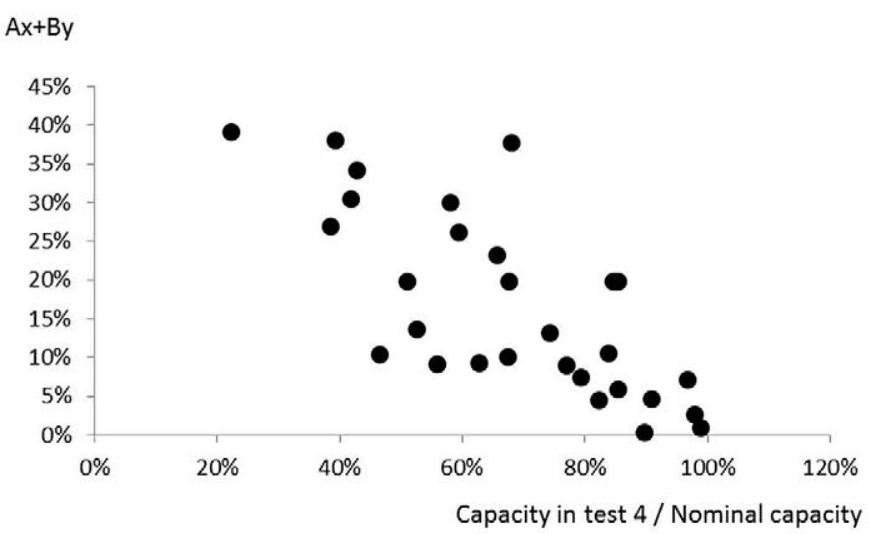

Fig. 13. Relationship between the degradation of the batteries $\left(C_{\mathrm{T} 4} / \mathrm{C}_{\mathrm{nom}}\right)$ and the combination of both the percentage of days of low battery disconnections $(x)$ and the average daily load percentage $(y)$ with respect to a normalized load of $20 \mathrm{Ah}$. $A$ and $B$ are two parameters calculated for the best fit model. The results lead that $A=0.42$ and $B=0.58$.

reference PV module [23,24], of the same model of the one from the sample. Thus, uncertainty due to thermal, angular and spectral responses is not an issue. As shown in Fig. 14, after cleaning both modules and waiting for cell temperature stabilization (both modules must reach similar temperature values), the capacitive load test is carried out when the effective irradiance is above $800 \mathrm{~W} / \mathrm{m}^{2}$ [24], in order to minimize uncertainty.

The main statistics of the results are summarized in Table 5 and Fig. 15 , where $\Delta \mathrm{I}_{\mathrm{m}}{ }^{*}$ is the variation of the maximum current with respect to the one from the flash report and $\Delta \mathrm{P}_{\mathrm{m}}{ }^{*}$ is the maximum power variation with regard to the same report.

The test shows a mean reduction of $\mathrm{P}_{\mathrm{M}}{ }^{*}$ in $6.7 \%$, and the standard deviation $\sigma=2.0 \%$.

We can deduce that the mean annual power $\left(\mathrm{P}_{\mathrm{M}}{ }^{*}\right)$ degradation corresponds to $1.1 \%$. However, PV modules can experience a premature degradation after the first hours of exposure to solar radiation. The possible early degradation is included in this yearly rate, since degradation in the first days of operation was never

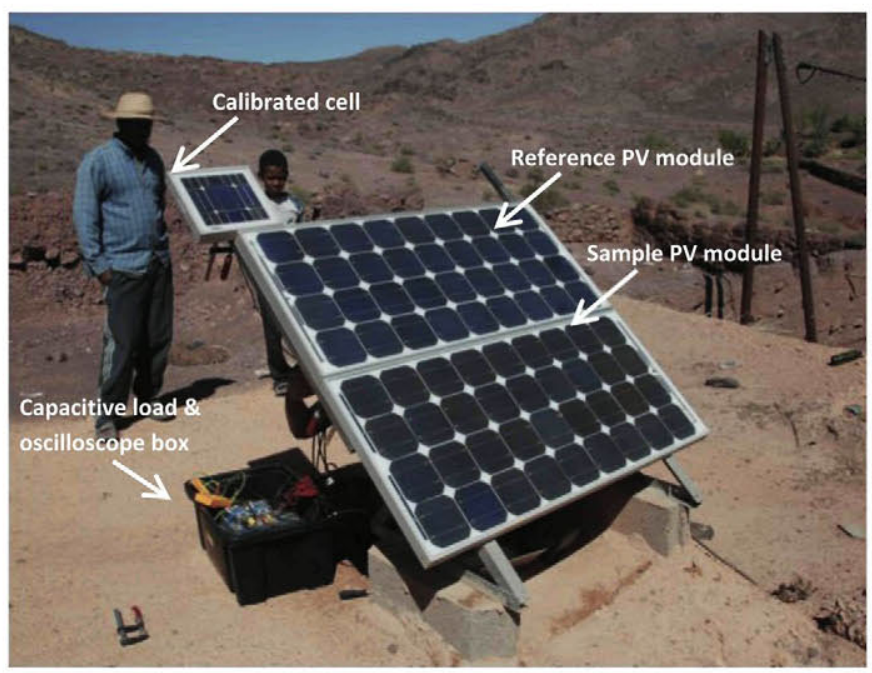

Fig. 14. Outdoor measurement equipment. The PV module below is one of the sample modules, and the upper one is the reference module. Both are stabilized in temperature before testing and they are installed in the same plane. The calibrated cell is used to check that the effective irradiance $G_{\text {eff }}$ is greater than $800 \mathrm{~W} / \mathrm{m}^{2}$ when carrying out the test. 
Table 5

Statistics of the PV modules degradation, in STC conditions, related to the data from the manufacturer flash report.

\begin{tabular}{lcc}
\hline & $\Delta \mathrm{l}_{m}^{*} \%$ & $\Delta \mathrm{P}_{m}^{*} \%$ \\
\hline Mean $(\mu)$ & -4.8 & -6.7 \\
Median & -5.0 & -6.7 \\
Standard deviation $(\sigma)$ & -1.6 & -2.0 \\
\hline
\end{tabular}

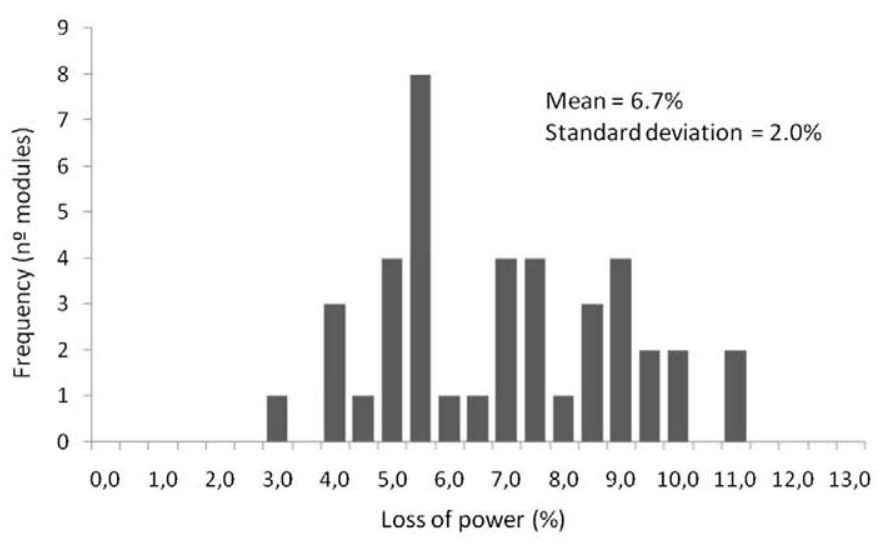

Fig. 15. Distribution of the measured loss of power of the 41 PV modules after 6.15 years of operation.

measured. Considering an early degradation in terms of maximum power $\mathrm{P}_{\mathrm{M}}{ }^{*}$ between $0 \%$ and $4 \%$ [25], we can conclude that the mean yearly degradation goes from $0.4 \%$ to $1.1 \%$, which is consequent with other reported experiences [26,27].

Inspection of hotspots has been carried out with a thermographic camera (model Infracam FLIR E60). The results show that only one PV module presented temperature variations $(\Delta T)$ between cells higher than $20^{\circ} \mathrm{C}$. That PV module had a $\Delta T$ of around $30^{\circ} \mathrm{C}$, reaching a hot-spot temperature of $86^{\circ} \mathrm{C}$ (see Fig. 16).
It has been observed, as well, some visual defects in a few PV modules, such as browning in the encapsulation EVA (ethylenevinyl-acetate) layer $[28,29]$, or defects in small areas of the antireflective coating in one cell [30], but because of its low frequency they have no statistical relevance in this study.

\section{Conclusions}

In order to analyse the battery degradation process, a sample of 40 batteries installed at the Moroccan PERG programme has been periodically tested over a period of 18 operation months. The main results are:

1. On average, the capacity drops to $60 \%$ of the initial capacity after eighteen months of operation. In less than six months the batteries have reached a remaining capacity lower than $80 \%$ of the nominal capacity, the threshold usually used to define the battery lifetime, which is not the case for PVRE users.

In spite of this fast degradation, past studies based on the O\&M database show that batteries keep working for much more time (MTTF $=5.5$ years) until the users perceive that the SHS does not satisfy their needs and ask for the replacement of the battery. Correlating these two results, a model has been proposed to calculate the remaining capacity that leads to user dissatisfaction, which is $18 \%$ of the initial capacity for this particular programme.

2. Based on current recorded data, it has been determined that there is no a standard load profile, but loads are in general very low as regards the storage capacity of the batteries. The mean load consumption has been $\mu_{\text {load }}=5.2 \mathrm{Ah} /$ day and the standard deviation $\sigma_{\text {load }}=4.2 \mathrm{Ah} /$ day. It must be noted that the design load was much higher (12 Ah/day), which could suggest that battery degradation would have been more accelerated if both, design and real loads had been closer. This leads to an operation normally based on a high SOC, with sporadic events of low battery disconnections. A model that correlates these two sorts of operation with the battery capacity degradation has been proposed.

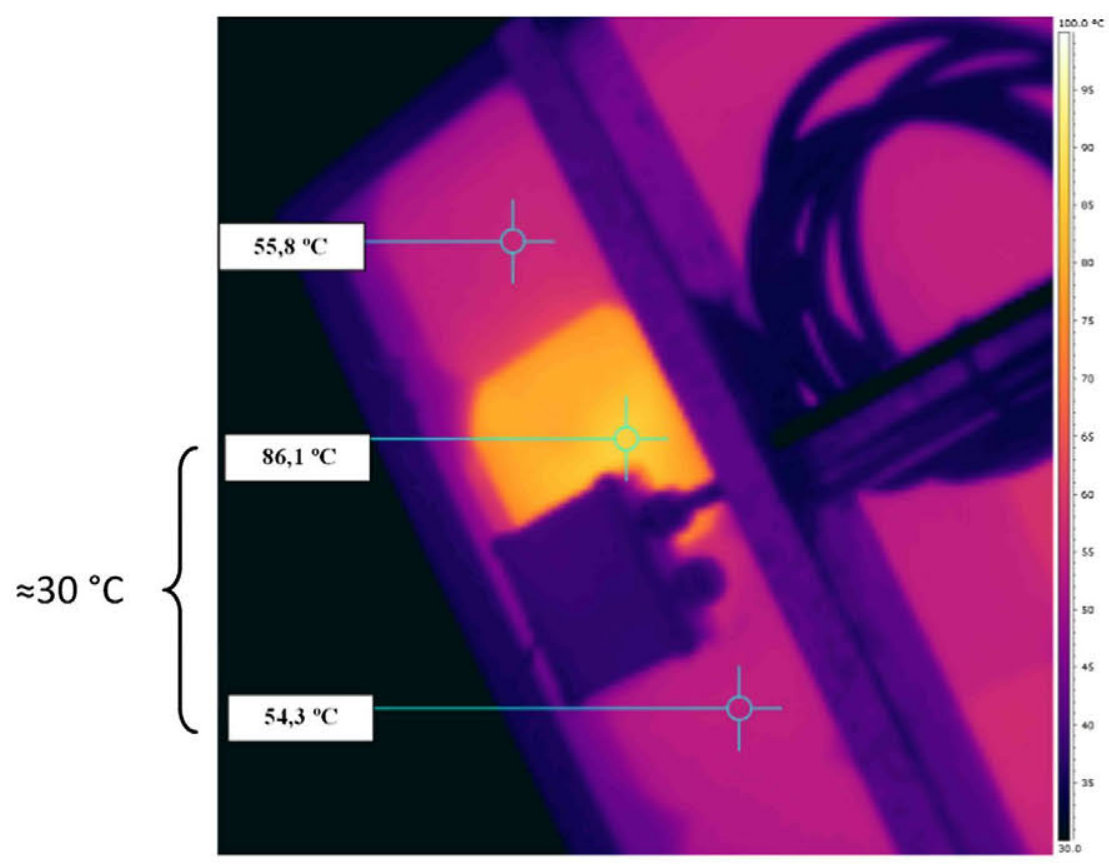

Fig. 16. Thermal image of the rear side of a PV module showing a hot cell $30^{\circ} \mathrm{C}$ higher than the other surrounding cells of the module. 
3. The reasons for this fast degradation of the battery capacity could be as follows:

- Bad manufacturing quality of batteries. The in-the-field testing has exhibited a rapid degradation of batteries even working with low loads. Moreover, they have shown wide dispersion in terms of capacity and density of electrolyte. Ultimately, the visual inspection of the plates from one of the most degraded batteries has shown the dramatic loss of active mass in the positive plate which suggests a very low physical resistance of the plates

- The behaviour of degraded batteries (with capacities of less than $0.8 \mathrm{C}_{\text {nom }}$ ) is difficult to predict. It makes very complex to adapt the algorithms of the charge controllers.

- The threshold of the charge controller to protect the battery against over discharge allows a DOD close to $100 \%$, which is completely incorrect, although this does not seem to be very relevant, since excessive loads are not common

The results and conclusions reported in this paper could lead to the question of the convenience of using local manufactured batteries in rural electrification programmes. It is assumed that manufacturing quality depends only of the quality process and raw materials used and not of the country, but it is also true that quality involves an increase in prices, and therefore, this must be adapted to the local markets. However, successful experiences have been proved in Brazil and Bolivia where local batteries have been used in PVRE programmes (according to author's own sources). Thus, the use of local batteries in general must not be excluded, but compliance with the minimum quality standards should be tested.

As regards the PV modules, a set of 41 mono-crystalline modules have been tested in the field to assess their state of quality, resulting in a mean power degradation rate of between $0.4 \%$ and $1.1 \%$ per year, which matches other experiences reported in the bibliography. Defects related to hotspots, broken diodes, browning and other defects are almost negligible. Hence, silicon PV modules show good reliability behaviour, especially when compared with the other SHS devices, such as batteries, lamps or charge controllers.

\section{Acknowledgements}

The authors thank Prof. Eduardo Lorenzo Pigueiras for their valuable contributions, suggestions, discussions and reviews that have made this work possible. This study has been partially financed by the Universidad Politécnica de Madrid (UPM) under the code project: 35_FOTOVOLT.

\section{References}

[1] Lemaire X. Off-grid electrification with solar home systems: the experience of a fee-for-service concession in South Africa. Energy Sustain Dev 2011;15(3): 277-83.

[2] Lemaire X. Fee-for-service companies for rural electrification with photovoltaic systems: the case of Zambia. Energy Sustain Dev 2009;13(1):18-23.

[3] Zomers A. The challenge of rural electrification. Energy Sustain Dev 2003; VII(1):69-76.

[4] IEA-PVPS T9-07. 16 cases studies on the deployment of photovoltaic technologies in developing countries; 2003. 1-115.

[5] Martinot E, Cabraal A, Mathur S. World Bank/GEF solar home system projects: experiences and lessons learned 1993-2000. Renew Sustain Energy Rev 2001;5(1):39-57.
[6] Interim report: Output 6. Are view of international literature of ESCOs and fee-for-service approaches to rural electrification (solar home systems). Cape Town: Energy \& Development Research Centre; 2003. p. 1-36.

[7] Chaurey A, Kandpal TC. Assessment and evaluation of PV based decentralized rural electrification: an overview. Renew Sustain Energy Rev 2010;14(8): $2266-78$.

[8] van der Vleuten F, Stam N, van der Plas R. Putting solar home system programmes into perspective: what lessons are relevant? Energy Policy 2007:35(3):1439-51.

[9] Djamin M, Dasuki AS, Lubis AY. Performance evaluation of solar home systems after more than ten years of operation in Indonesia, World renewable Energy Congress VI2000; 2022-2025.

[10] Nieuwenhout FDJ, van Dijk AL, Lasschuit PE, van Roekel GM, van Dijk VAP, Hirsch D, et al. Experience with solar home systems in developing countries: a review. Prog Photovoltaics Res Appl 2001;9:455-74.

[11] Cabraal A, Cosgrove-Davies M. Schaeffer L. Best practices for photovoltaic household electrification programs: lessons from experiences in selected countries, World bank technical paper number 324. Asia Technical Department Series; 1996. 1-103.

[12] Carrasco LM, Narvarte L, Lorenzo E. Operational costs of a 13,000 solar home systems rural electrification programme. Renew Sustain Energy Rev 2013;20(0):1-6. http://dx.doi.org/10.1016/j.rser.2012.11.073 [2012].

[13] Carrasco LM, Narvarte L, Peral A, Vázquez M. Reliability of a 13,000-SHS photovoltaic rural electrification programme. Prog Photovoltaics Res Appl 2013;21:1136-45. http://dx.doi.org/10.1002/pip.2218.

[14] http://www.almabat.ma/ (Accessed April 2014).

[15] http://www.phocos.com/ (Accessed April 2014)

[16] Egido MA, Lorenzo E, Narvarte I. Universal technical standard for solar home systems. Prog Photovoltaics: Res Appl 1998;6:315-24.

[17] O'Connor P, Kleyner A. Practical reliability engineering. Chichester, UK: Wiley; 2011.

[18] IEC standard 60896-11. Stationary lead-acid batteries - Part 11: vented types - general requirements and methods of tests; 2002.

[19] IEC standard 61427-1. Secondary cells and batteries for renewable energy storage - general requirements and methods of test - Part 1: photovoltaic offgrid application. Edition 1.0 (2013-04-23)

[20] Sauer DU. Electrochemical storage for photovoltaics, in handbook of photovoltaic science and engineering. In: Luque A, Hegedus S, editors. Chichester, UK: John Wiley \& Sons, Ltd; 2015. p. 896-951. 10.1002/ 0470014008.ch18.

[21] Muñoz. J, Lorenzo E. Capacitive load based on IGBTs for on-site characterization of PV arrays. Sol Energy 2006;80(11):1489-97. http://dx.doi.org/ $10.1016 / \mathrm{j}$.solener.2005.09.013.

[22] IEC standard 60904-1. Photovoltaic devices - part 1: measurement of photovoltaic current-voltage characteristics; 2006.

[23] International standard IEC 60891. Photovoltaic devices - Procedures for temperature and irradiance corrections to measured I-V characteristics. International Electrotechnical Commission; 2009.

[24] Moreton Viungra R, Lorenzo E, Martinez-Moreno F. Field Performance of PV modules quality control process, 23rd European Photovoltaic Solar Energy Conference and Exhibition 2008; Valencia, Spain, http://dx.doi.org/10.4229/ 23rdEUPVSEC2008-4AV.3.33.

[25] Nofuentes G, Aguilera J, Santiago RL, De La Casa J, Hontoria L. A referencemodule-based procedure for outdoor estimation of crystalline silicon PV module peak power. Prog Photovoltaics Res Appl 2006;14:77-87. http:// dx.doi.org/10.1002/pip.636.

[26] Muñoz-García MA, Silva JP, Chenlo F. Influence of initial power stabilization over PV modules maximum power, 24th European Photovoltaic Solar Energy Conference 21-25 September 2009; Hamburg, Germany, http://dx.doi.org/10. 4229/24thEUPVSEC2009-4AV.3.50.

[27] Munoz MA, Alonso-García MC, Vela N, Chenlo F. Early degradation of silicon PV modules and guaranty conditions. Sol Energy 2011:85(9):2264-74.

[28] Pern FJ, Czanderna AW. Characterization of ethylene vinyl acetate (EVA) encapsulant: effects of thermal processing and Weathering degradation on its Discoloration. Sol Energy Mater Sol Cells 1992;25:3-23. http://dx.doi.org/ 10.1016/0927-0248(92)90013-F.

[29] Berman D, Biryukov S, Faiman D. EVA laminate browning after 5 years in a grid-connected, mirror-assisted, photovoltaic system in the Negev desert: effect on module efficiency. Sol Energy Mater Sol Cells 1995;36(4): $421-32$.

[30] Sánchez-Friera P, Piliougine M, Peláez J, Carretero J,Sidrach de Cardona M Analysis of degradation mechanisms of crystalline silicon PV modules after 12 years of operation in Southern Europe. Progress in Photovoltaics Res Appl 2011;19:658-66. http://dx.doi.org/10.1002/pip.1083. 